\title{
Instantaneous and Long-term Lighting Design Metrics for Higher Education Buildings in a Tropical Climate
}

\author{
Zhe Kong ${ }^{1}$, J. Alstan Jakubiec ${ }^{2}$ \\ ${ }^{1}$ Southeast University, Nanjing, China \\ ${ }^{2}$ University of Toronto, Toronto, Canada
}

\begin{abstract}
This paper presents a study that explores instantaneous and long-term lighting design metrics based on subjective evaluations within higher educational buildings in a tropical weather. Three types of classrooms-computer labs, collaborative spaces, and lecture halls-were studied. Lighting simulation models were calibrated and validated using measurements taken onsite and utilized to generate both instantaneous and annual climate-based lighting predictors. Four hundred and thirty-nine participants' responses to online questionnaires were collected. From an analysis of this data, the authors recommend instantaneous horizontal illuminance of $150 \mathrm{~lx}$ and vertical illuminances of $200 \mathrm{~lx}$ as the lighting thresholds for classrooms access to daylight, which result in $80 \%$ of occupants reporting imperceptible or noticeable daylight glare, as well as $53 \%$ of occupants comfortable with daylighting environments. Annual mean vertical illuminance of $200 \mathrm{~lx}$ during the daytime leads to $85 \%$ of occupants satisfied with annual access to daylight. Daylight falling on monitors should be controlled around 100 lx or lower to satisfy at least $70 \%$ of occupants and reduce reflections in monitors. For classrooms under electric lighting, horizontal illuminance of $200 \mathrm{~lx}$ and vertical illuminance of $250 \mathrm{~lx}$ are recommended to achieve visual comfort for $60 \%$ of occupants and visual discomfort for $7 \%$ of occupants.
\end{abstract}

\section{Introduction}

Lighting has an important impact on comfort, learning, and task performance as has been alluded to by many researchers. Heschong et al. (2002 and 2007) demonstrated the improvement of students' performance associated with sufficient and uniform daylight and later proposed the positive correlation between student performance and horizontal illuminance under daylight. Theodorson (2009) demonstrated the importance of daylight from teachers' perspectives. Dunn et al. (1985) suggested designing lighting environments according to an individual's needs. Although many studies have demonstrated lighting's positive influence on student performance, insufficient research explores lighting design thresholds from the occupant's perspective in educational spaces.

Instead of employing the same visual discomfort and lighting design thresholds for all countries and contexts, recent research has shown that occupant preferred lighting levels are influenced by the climactic context. Although Wienold et al. concluded Daylight Glare Probability (DGP)'s highest performance in lab studies globally (2019), Mangkuto et al. (2017) suggested much lower Daylight Glare Probability (DGP) thresholds for detecting results from perceptible to intolerable glare in Indonesia. Hiring et al. (2017) proposed the ratio of window to background luminance as the more sensitive measure of occupant discomfort under tropical skies. Dahlan et al. (2009) concluded that participants accepted dimmer daylighting environments in Malaysia. These previous studies show the necessity of exploring daylighting design metrics under tropical skies for educational facilities.

Despite the fact that many studies focusing on instantaneous lighting metrics (Hirning, Isoardi, \& Garcia-Hansen, 2017; Jakubiec, Reinhart \& Van Den Wymelenberg, 2015; Van Den Wymelenberg, 2012; Wienold \& Christoffersen, 2006) limited studies have explored long-term lighting metrics. Wienold proposed a simplified method of calculating annual DGP and defined the annual daylight glare comfort classes without subjective assessments (Jan Wienold, 2009). Similarly as Useful Daylight Illuminance (UDI) (Nabil \& Mardaljevic, 2006) and Daylight Autonomy (DA) (Reinhart, Mardaljevic, \& Rogers, 2006; Reinhart \& Walkenhorst, 2001), Spatial Daylight Autonomy \& Annual Sunlight Exposure (IES-LM-83, 2012) proposed annual climatebased metric of avoiding direct sunlight without further proof involving occupant subjective evaluations. Jakubiec and Reinhart (2016) proposed an annual discomfort glare model specific to the site and participants in their study. Rockcastle and Andersen (2014) suggested imagebased annual spatial contrast and annual luminance variability as a metric by simulating ten conceptualized spaces without subjective evaluations.

This study aims to fill the gap by combining detailed physical measurements, correlations with occupant subjective data on perception, and an investigation of instantaneous and long-term simulation metrics used in design. This research investigates lighting metrics within three types of classrooms in Singapore. Lighting data within 12 classrooms were measured or simulated. Fourhundred and thirty-nine participants evaluated their instantaneous and long-term lighting experience within the 12 classrooms. One aim of this paper is to examine the effectiveness of existing lighting design metrics in terms 
of predicting subjective assessments. The other aim is to propose appropriate lighting design metrics for higher education spaces in tropical climates.

\section{Method}

\section{Subjective survey}

Computer labs, collaborative learning spaces, and lectue halls were studied at the Singapore University of Technology and Design (SUTD) (1.3N, 104.0E) and Building and Construction Authority Academy (BCAA) $(1.3 \mathrm{~N}, 103.9 \mathrm{E})$. For each classrooms, participants were asked for their consent to undertake a 5-minute online survey at the beginning or end of a class. For two computer labs and four collaborative spaces at SUTD, participants filled the survey under only daylighting condition while electric lights were off. For two other computer labs at BCAA and four lecture halls, participants filled the survey under electric lighting as the rooms had no daylight access. The collection of survey responses started in September 2017 and ended in November 2018. Each questionnaire asked a participant to indicate his or her current seating position when filling the survey and his or her regular seating positions based on a provided floorplan layout. Then, questions associated with instantaneous and long-term visual comfort and satisfaction with daylight levels were asked. With the limit of space, the authors present only six questions in this paper, as shown in Table 1, along with the corresponding data analysis.

Table 1: Select questions and response options in the subjective survey.

\begin{tabular}{|c|c|}
\hline Question & Response \\
\hline \multicolumn{2}{|c|}{ Instantaneous Evaluation Questions } \\
\hline $\begin{array}{l}\text { 1. Mark the degree of glare you } \\
\text { experienced while taking this } \\
\text { survey. }\end{array}$ & $\begin{array}{c}\text { Imperceptible (No glare), } \\
\text { Noticeable (Little glare), } \\
\text { Disturbing (Significant glare), } \\
\text { Intolerable (Extreme glare) }\end{array}$ \\
\hline $\begin{array}{l}\text { 2. Assuming you have to } \\
\text { conduct your daily work under } \\
\text { the current conditions, do you } \\
\text { feel that the lighting is }\end{array}$ & $\begin{array}{c}\text { Clearly comfortable, } \\
\text { Comfortable, Just comfortable, } \\
\text { Neutral, Just uncomfortable, } \\
\text { Uncomfortable, Clearly } \\
\text { uncomfortable }\end{array}$ \\
\hline $\begin{array}{l}\text { 3. Indicate the cause(s) or } \\
\text { source(s) if you are } \\
\text { experiencing glare or visual } \\
\text { discomfort. }\end{array}$ & $\begin{array}{l}\text { Reflections in computer screen, } \\
\text { Window, Shading device, } \\
\text { Electric lighting, Personal desk } \\
\text { lamp, Other (Indicate) }\end{array}$ \\
\hline $\begin{array}{l}\text { 4. Currently, which adjectives } \\
\text { describe the lighting in your } \\
\text { current location? }\end{array}$ & $\begin{array}{c}\text { Gloomy, Dim, Comfortable, } \\
\text { Bright, Glary }\end{array}$ \\
\hline \multicolumn{2}{|c|}{ Long-term Evaluation Questions } \\
\hline $\begin{array}{l}\text { 5. How satisfied are you with } \\
\text { your access to daylight? }\end{array}$ & $\begin{array}{l}\text { Very satisfied, Satisfied, A little } \\
\text { satisfied, Neutral, A little } \\
\text { dissatisfied, Dissatisfied, Very } \\
\text { dissatisfied }\end{array}$ \\
\hline $\begin{array}{l}\text { 6. The lighting quality in the } \\
\text { space positively influences my } \\
\text { productivity at work. }\end{array}$ & $\begin{array}{c}\text { Strongly agree, Agree, A little } \\
\text { agree, Neither agree nor } \\
\text { disagree, A little disagree, } \\
\text { Disagree, Strongly disagree }\end{array}$ \\
\hline
\end{tabular}

Space Measurement and Lighting Model Calibration

The computer labs and collaborative spaces have exterior windows and access to daylight, while the lecture halls only have electric lights without exterior windows. Table 2 lists 12 studied classrooms' dimension, orientation, window to wall ratio (WWR), glazing transmittance, and seating capacity. With small WWR and low glazing transmittance, two computer labs at BCAA were considered under primary electric lighting.

Table 2: Twelve classrooms' detailed information.

\begin{tabular}{|c|c|c|c|c|c|}
\hline \multicolumn{6}{|c|}{ Computer Labs at SUTD } \\
\hline No. & $\begin{array}{l}\text { Size } \\
(\mathbf{m})\end{array}$ & Orient. & WWR & $\begin{array}{l}\text { Glazing } \\
\text { trans. }\end{array}$ & $\begin{array}{l}\text { Seat } \\
\text { No. }\end{array}$ \\
\hline 1 & $\begin{array}{c}15.5 \text { by } \\
10.3\end{array}$ & East \& West & $\begin{array}{l}48.4 \% \\
58.6 \% \\
\end{array}$ & $83.7 \%$ & 40 \\
\hline 2 & $\begin{array}{c}15.6 \text { by } \\
15.3\end{array}$ & East \& West & $47.1 \%$ & $83.7 \%$ & 50 \\
\hline \multicolumn{6}{|c|}{ Computer Labs at BCAA } \\
\hline 3 & $\begin{array}{c}8.2 \text { by } \\
9.4\end{array}$ & South & $3.5 \%$ & $54.7 \%$ & 40 \\
\hline 4 & $\begin{array}{c}8.2 \text { by } \\
9.4\end{array}$ & South & $3.5 \%$ & $54.7 \%$ & 40 \\
\hline \multicolumn{6}{|c|}{ Collaborative Spaces at SUTD } \\
\hline 5 & $\begin{array}{c}12.5 \text { by } \\
17\end{array}$ & $\begin{array}{l}\text { Northeast } \\
\text { Southwest }\end{array}$ & $\begin{array}{l}51.1 \% \\
56.5 \%\end{array}$ & $61.7 \%$ & 128 \\
\hline 6 & $\begin{array}{c}12.6 \text { by } \\
8.6\end{array}$ & North South & $73 \%$ & $61.5 \%$ & 30 \\
\hline 7 & $\begin{array}{c}14.8 \text { by } \\
28.7\end{array}$ & East \& West & $55.6 \%$ & $\begin{array}{c}61.6 \% \& \\
41.6 \% \\
\end{array}$ & 43 \\
\hline 8 & $\begin{array}{c}12.5 \text { by } \\
8.5\end{array}$ & $\begin{array}{l}\text { Northeast } \\
\text { Southwest }\end{array}$ & $\begin{array}{l}53.5 \% \\
58.7 \% \\
\end{array}$ & $64.4 \%$ & 64 \\
\hline \multicolumn{6}{|c|}{ Lecture Halls at SUTD } \\
\hline 9 & $\begin{array}{c}10.7 \text { by } \\
17.1\end{array}$ & -- & -- & -- & 60 \\
\hline 10 & $\begin{array}{c}12.7 \text { by } \\
13.7 \\
\end{array}$ & -- & - & -- & 148 \\
\hline 11 & $\begin{array}{c}12.7 \text { by } \\
13.7\end{array}$ & -- & -- & -- & 145 \\
\hline \multicolumn{6}{|c|}{ Lecture Halls at BCAA } \\
\hline 12 & $\begin{array}{c}16.3 \text { by } \\
10.2\end{array}$ & - & -- & -- & 128 \\
\hline
\end{tabular}

For computer labs and collaborative spaces, three to six seating positions were randomly selected to record instantaneous luminance distributions via the High Dynamic Range (HDR) image technique (Inanici, 2006). We also followed the recommended guidelines from Jakubiec et al's (2016a and 2016b) studies to ensure the accuracy of HDR images. A 3D scanner was used to record the geometric information of the interior spaces and exterior surrounding environments. A spectrophotometer was used to measure interior and exterior material reflectance and specularity. Glazing transmittances were measured onsite by comparing vertical illuminance measurements on both sides of the glazing. Monitors and electric lights in computer labs were calibrated separately based on the HDR images. In addition to a plastic casing, a monitor was comprised of three layers: high-state pixels, low-state pixels, and a translucent screen (Jones \& Reinhart, 2016). A monitor's 
calibrated Radiance materials for one classroom are listed in Table 3. Figure 1 illustrates the field measure and simulated luminance map in one computer lab. Table 4 presents the representative falsecolor luminance images of measured HDR and simulated images for computer labs and collaborative spaces. Lecture halls only include measured HDR images as no dynamic daylighting necessitated a simulation model. Simulated vertical illuminance $\left(\mathrm{E}_{\mathrm{v}}\right)$ was compared to measured $\mathrm{E}_{\mathrm{v}}$. For two computer labs and four collaborative spaces under daylit conditions, 27 groups of illuminance calibration data resulted in a Mean Bias Error (MBE) of 3.1\% and a Root Mean Square Error (RMSE) of $16.8 \%$ of the mean measured vertical illuminance. For two computer labs under electric lighting, 9 groups of calibration data resulted in a MBE of $10.1 \%$ and RMSE of $15 \%$ of the mean measured vertical illuminance. As the simulated $\mathrm{E}_{\mathrm{v}}$ resulted in MSE and RMSE lower than 20\%, the simulated lighting data generated by the calibrated models can accurately represent real lighting environments (Jones \& Reinhart, 2015; Kong, Utzinger, \& Humann, 2018).

Table 3: Monitor Radiance material properties.

\begin{tabular}{|c|c|}
\hline $\begin{array}{c}\text { Translucent } \\
\text { screen }\end{array}$ & $\begin{array}{c}\text { void trans MonitorTrans } \\
\text { High pixel }\end{array}$ \\
\hline Low pix & 0.5250 .5250 .5250 .04400 .991 \\
\hline Dark case & 040.279330 .279330 .279330 \\
\hline Light case & 0040.033520 .033520 .033520 \\
\hline & void glow LowPixel \\
\hline & 050.0540 .0540 .0620 .0130 .05 \\
\hline
\end{tabular}

Table 4: Falsecolor images of HDR images and associated simulated luminance maps for computer labs and collaborative spaces, along with HDR images for lecture halls.



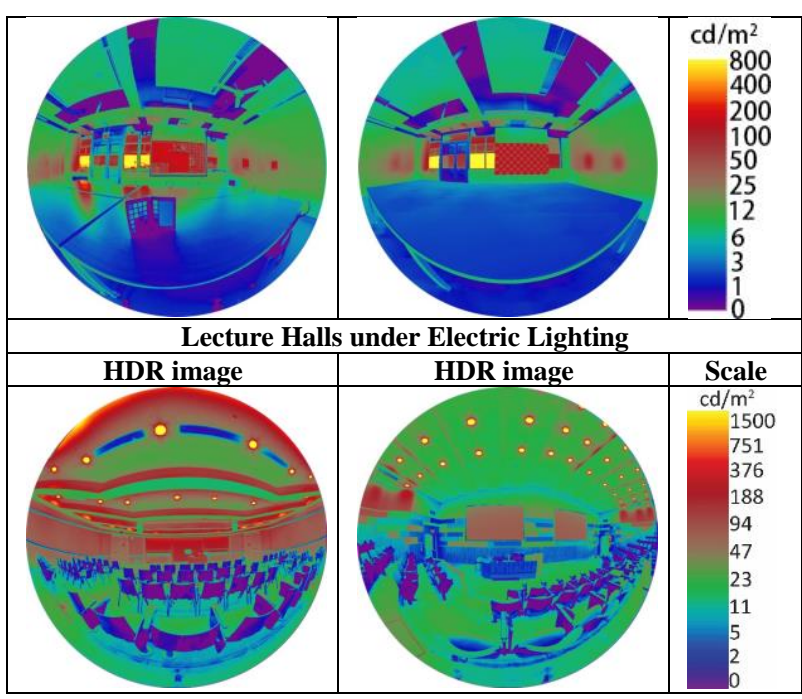

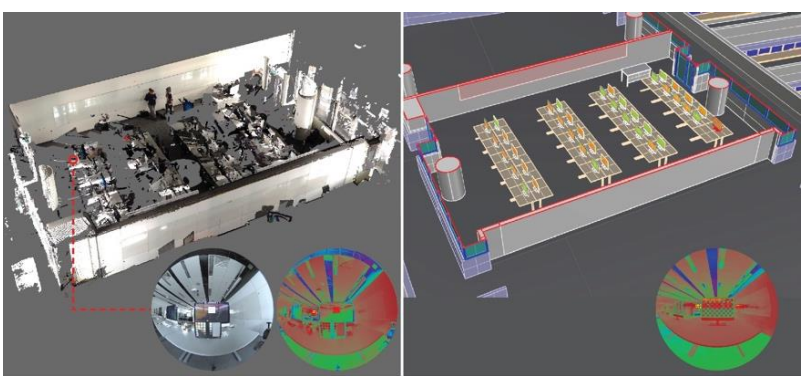

Figure 1: 3D scan of a computer lab and HDR measurement (left) and the lighting model and simulated luminance maps (right).

According to participants' reporting of their instantaneous and regular seating positions, both instantaneous and annual climate-based simulations were generated for computer labs and collaborative spaces using the accurately calibrated simulation models. Weather data was extracted from a weather station located at SUTD. Custom 5-minute Daysim-format weather files were created for the year of data including the survey period. Annual lighting predictors corresponding to each participant were calculated by averaging simulated annual lighting predictors at his or her regular seating positions.

\section{Data analysis}

For instantaneous lighting predictors, horizontal illuminance on a working plane $\left(\mathrm{E}_{\mathrm{h}}\right)$ and vertical eye illuminance $\left(E_{v}\right)$ were either simulated using the calibration models for computer labs and collaborative spaces or measured under electric lighting conditions within lecture halls. Extracted from either simulated luminance maps for computer labs and collaborative spaces or HDR images taken within lecture halls, luminance-based lighting predictors were calculated from three areas: an entire scene, the $40^{\circ}$ horizontal band, and the monitor area only for computer labs (Figure 2). Based on an entire scene, the mean luminance $\left(\mathrm{L}_{\text {mean }}\right)$ and results of daylight glare indices, including Daylight Glare Index (DGI) (Hopkinson, 1972), Unified Glare Rating (CIE Technical Committee, 1995), and Daylight Glare Probability (Jan Wienold \& Christoffersen, 2006), were calculated for correlation analysis. Based on the horizontal $40^{\circ}$ band, the mean luminance $\left(\mathrm{Band}_{\text {mean }}\right)$ was 
selected due to its ability of quantifying 'visual lightness' (Loe, Mansfield, \& Rowlands, 1994) and its strong regression with subjective visual comfort (K. G. Van Den Wymelenberg, 2012). The maximum luminance $\left(\right.$ Band $\left._{\max }\right)$, luminance standard deviation $\left(\right.$ Band $\left._{\text {std }}\right)$, and coefficient of variation (COV) of luminance (Band ${ }_{\mathrm{COV}}$ ) (Mahić, Galicinao, \& Van Den Wymelenberg, 2017) were extracted. In order to extract reflective luminance values in monitors, monitor luminance were simulated without any light source. Then, reflective luminance values were calculated by subtracting the monitor luminance from the instantaneous simulated luminance map. The mean luminance in reflections $\left(\operatorname{Ref}_{\text {mean }}\right)$, luminance percentiles in reflections $\left(\operatorname{Ref}_{\mathrm{Nth}}\right)$, and the percent of a screen with reflections over predetermined luminance thresholds $\left(\operatorname{Ref}_{\mathrm{Nper}}\right)$ were calculated for analysis. Contrast ratios in monitors were calculated following Equation (1), as shown below:

$$
C R_{V}=\frac{L_{H}+L_{r}}{L_{L}+L_{r}}
$$

where $\mathrm{L}_{\mathrm{H}}$ is the high-pixel values on a monitor, $\mathrm{L}_{\mathrm{L}}$ is the low-pixel values on a monitor, and $\mathrm{L}_{\mathrm{r}}$ is the luminance distribution from reflected light.

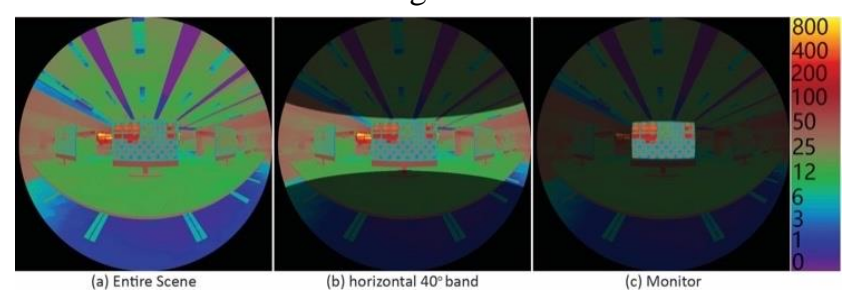

Figure 2: Analysis areas for instantaneous lighting predictors.

For annual lighting predictors, three basic illuminancebased predictors, $E_{h}, E_{v}$, and illuminance falling on a monitor $\left(\mathrm{E}_{\mathrm{m}}\right)$, were simulated annually at 5-minute intervals at each workstation. Then, annual lighting predictors at each seating position, like annual mean horizontal and vertical illuminance, along with Daylight Autonomy (DA) at $500 \mathrm{~lx}$ of $\mathrm{E}_{\mathrm{h}}, \mathrm{E}_{\mathrm{v}}$, and $\mathrm{E}_{\mathrm{m}}$, were calculated. Finally, annual lighting predictors associated with a participant were calculated by averaging all his or her regular seating positions. As no simulation model was built for lecture halls due to constant electric lighting conditions, horizontal and vertical illuminance were directly measured with the electric lighting at full power. Annual lighting predictors were also obtained by averaging measured lighting predictors at a participant's regular seating positions.

In this paper, a simple correlation between a single simulated or measured lighting predictor and a surveyed subjective evaluation was analyzed. Subjective responses were grouped based on a corresponding lighting predictor that was numerically ordered and grouped. Then, the correlation between the mean lighting predictor of each group and the percent of participants selecting a predetermined question option was sought. For example, 130 responses for the computer labs under daylight were divided into 11 groups with each group between 11 and 12 responses $(\sqrt{130}=11.4)$. Groups are divided based on quantiles of the simulated or measured lighting predictors. This data analysis method has been commonly used in lighting studies seeking correlations between subjective assessments and lighting predictors (Hirning, Isoardi, \& Garcia-Hansen, 2017; Jakubiec, Quek, \& Srisamranrungruang, 2018; Jan Wienold \& Christoffersen, 2006).

\section{Results}

\section{Demographic}

A hundred and eighty-eight valid responses to the survey were analyzed for the computer labs, 130 of which were collected within two computer labs under daylight, while 58 of which were collected within two other computer labs under primary electric lights with minimal daylight. Furthermore, 157 valid responses were collected within four collaborative spaces under daylight, and 94 valid responses were collected within four lecture halls under only electric lighting conditions. The total responses within three types of classrooms were 439. Table 5 shows participants' age, gender, and use of eyewear. Since the research focused on higher educational buildings, over $98 \%$ of the participants for three types of classrooms were between 18 and 30 years of age. Females roughly outnumbered males at a 2:1 ratio. Around a quarter of participants for each type of classroom did not wear either contacts or glasses while taking the survey.

Table 5: Demographic information for three types of classrooms.

\begin{tabular}{|c|c|c|c|c|c|}
\hline \multicolumn{6}{|c|}{ Computer Labs } \\
\hline \multicolumn{2}{|l|}{ Age } & \multicolumn{2}{|c|}{ Gender } & \multicolumn{2}{|c|}{ Eyewear } \\
\hline $18-20$ years & $23.5 \%$ & Male & $35.6 \%$ & Contacts & $13.3 \%$ \\
\hline 21-30 years & $75.4 \%$ & Female & $64.4 \%$ & Glasses & $60.6 \%$ \\
\hline $31-40$ years & $1.1 \%$ & & & None & $26.1 \%$ \\
\hline \multicolumn{6}{|c|}{ Collaborative Spaces } \\
\hline \multicolumn{2}{|l|}{ Age } & \multicolumn{2}{|c|}{ Gender } & \multicolumn{2}{|c|}{ Eyewear } \\
\hline $18-20$ years & $17.8 \%$ & Male & $36.3 \%$ & Contacts & $9.6 \%$ \\
\hline $21-30$ years & $80.9 \%$ & Female & $63.7 \%$ & Glasses & $68.2 \%$ \\
\hline $31-40$ years & $1.3 \%$ & & & None & $22.3 \%$ \\
\hline \multicolumn{6}{|c|}{ Lecture Halls } \\
\hline \multicolumn{2}{|l|}{ Age } & \multicolumn{2}{|c|}{ Gender } & \multicolumn{2}{|c|}{ Eyewear } \\
\hline $18-20$ years & $25.5 \%$ & Male & $35.1 \%$ & Contacts & $10.6 \%$ \\
\hline 21-30 years & $73.4 \%$ & Female & $64.9 \%$ & Glasses & $59.6 \%$ \\
\hline $31-40$ years & $1.1 \%$ & & & None & $29.8 \%$ \\
\hline
\end{tabular}

\section{Physical Lighting Data}

Table 6 presents the mean, maximum, minimum, and standard deviations of instantaneous $E_{h}$ and $E_{v}$ for four groups of data. Both two computer labs and four collaborative spaces under daylight presented greater $E_{h}$ and $E_{v}$ variations with relatively lower mean $E_{h}$ and $E_{v}$. Instantaneous $E_{v}$ range for collaborative spaces varied between 196.4 and $1390.3 \mathrm{~lx}$ with the greatest standard deviation of $230.1 \mathrm{~lx}$. Unlike the simulation models of computer labs, the simulation models of collaborative spaces had no monitors; therefore, collaborative spaces presented greater $\mathrm{E}_{\mathrm{v}}$ than computer labs. On the contrary, two computer labs and four lecture halls under electric lighting presented clustered distribution of $\mathrm{E}_{\mathrm{h}}$ and $\mathrm{E}_{\mathrm{v}}$ with 
greater mean $E_{h}$ and $E_{v}$. Lecture halls had the greatest mean $\mathrm{E}_{\mathrm{v}}$ of $410.1 \mathrm{~lx}$.

Table 6: Mean, maximum, minimum, and standard deviations of instantaneous $E_{h}$ and $E_{v}$ for four groups of data.

\begin{tabular}{|c|c|c|c|c|c|c|c|c|}
\hline \multirow{2}{*}{ Computer labs under daylight } & \multicolumn{4}{|c|}{$\mathbf{E}_{\mathbf{h}}$} & \multicolumn{4}{|c|}{$\mathbf{E}_{\mathbf{v}}$} \\
\cline { 2 - 9 } & Mean & Max. & Min. & S.D. & Mean & Max. & Min. & S.D. \\
\hline Computer labs under electric lighting & 128.8 & 689.4 & 27.1 & 123.4 & 120.1 & 342.9 & 53.4 & 55.3 \\
\hline Collaborative spaces under daylight & 281.6 & 430.2 & 133.8 & 64.6 & 121.5 & 201.1 & 29.1 & 30.2 \\
\hline Lecture halls under electric lighting & 112.3 & 919.4 & 11.2 & 105.8 & 196.4 & 1390.3 & 17.4 & 203.1 \\
\hline
\end{tabular}

\section{Inferential Statistics for Instantaneous Subjective Assessments}

Within three types of classrooms, simulated and measured instantaneous lighting predictors were correlated with participants' current subjective responses. All the data analysis listed in this paper were statistically significant correlated with the p-value lower than 0.05 or 0.1 . Given that $\mathrm{R}^{2}>0.25$ is moderate effect and $\mathrm{R}^{2}>0.64$ is strong effect, most of the correlations shown in Table 7 or the rest presented moderate or strong effect size. Table 7 shows the representative lighting predictors correlated with the percent of participants comfortable or uncomfortable with their instantaneous lighting environments Questions 2 and 4 in Table 1. For computer labs under daylight, both the $\log _{10}$ of $E_{v}$ and the $\log _{10}$ of Band $_{\text {std }}$ were positively correlated with the percent of occupants comfortable with daylighting environments. An $\mathrm{E}_{\mathrm{v}}$ of 250 lx resulted in $58.8 \%$ of occupants comfortable with daylighting environments. Band $\mathrm{std}_{\mathrm{st}}$ of $2001 x$ resulted in $45.1 \%$ of occupants comfortable with daylighting environments. For computer labs under electric lighting, greater DGI falling between 8.6 and 15.3, lower than the prescribed threshold of 18 to identify noticeable glare. Greater DGI values between 8.6 and 15.3 led to higher percent of occupants comfortable with electric lighting environments. Figure 3 shows the correlation between the $\log _{10}$ of $E_{\mathrm{v}}$ and the percent of occupants comfortable or uncomfortable with electric lighting environments within lecture halls. An $\mathrm{E}_{\mathrm{v}}$ of 250 lx resulted in $60.1 \%$ of occupants comfortable with lighting environments, $7.4 \%$ of occupants uncomfortable with lighting environments, and the remaining occupants holding neutral attitudes.

Table 7: Correlations between selected lighting measures and the percent of participants comfortable with their lighting environments.

\begin{tabular}{|c|c|c|c|}
\hline \multicolumn{4}{|c|}{ Computer Labs under Daylight } \\
\hline \multirow{3}{*}{ Comfortable } & Equation & $\mathrm{p}$-value & $\mathrm{R}^{2}$ \\
\cline { 2 - 4 } & $\mathrm{y}=57 * \log _{10}\left(\mathrm{E}_{\mathrm{v}}\right)-77.86$ & 0.0146 & 0.4476 \\
\cline { 2 - 4 } & $\mathrm{y}=35.49 * \log _{10}\left(\right.$ Band $\left._{\mathrm{std}}\right)-$ & 0.0522 & 0.2857 \\
36.52 & & \\
\hline \multicolumn{4}{|c|}{ Pomputer Labs under Electric Lighting } \\
\hline Comfortable & $\mathrm{y}=5.678 *$ DGI-11.874 & 0.0717 & 0.4112 \\
\hline \multicolumn{4}{|c|}{ Lecture Halls under Electric Lighting } \\
\hline & Predictor & $\mathrm{p}$-value & $\mathrm{R}^{2}$ \\
\hline
\end{tabular}

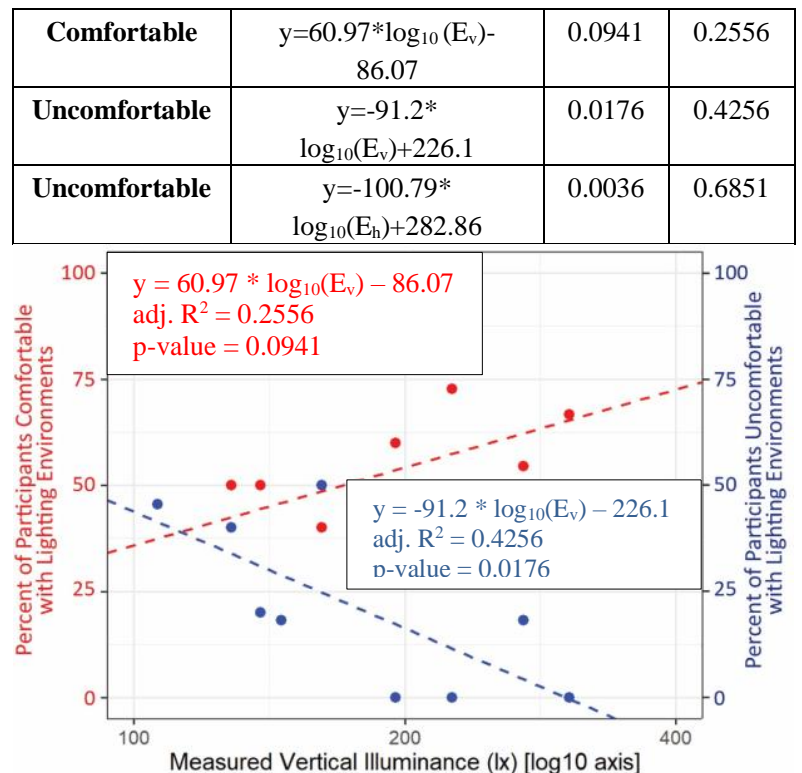

Figure 3: Correlations between vertical illuminance and the percent of participants comfortable with (red) or uncomfortable with (blue) instantaneous lighting environments for lecture halls under electric lighting.

The percent of participants reporting disturbing or intolerable glare for computer labs under daylight, for computer labs under primary electric lighting, for collaborative spaces, and for lecture halls were $23.3 \%$, $12.3 \%, 15.5 \%$, and $17.2 \%$, respectively. However, none of the DGP result for all 439 simulated or measured scenes was greater than 0.35 , the defined value to identify perceptible (noticeable) glare (Jan Wienold \& Christoffersen, 2006). UGR (CIE Technical Committee, 1995), a contrast-based glare, accurately predicted subjective evaluations of disturbing or intolerable glare varying between $0 \%$ and $21.1 \%$. Considering these low accuracy predicted by existing glare indices and thresholds, new, simple lighting predictors were derived from this study. Table 8 shows that $\mathrm{E}_{\mathrm{h}}$ was correlated with participants reporting imperceptible or noticeable glare as well as disturbing or intolerable glare-Question 1 in Table 1 - for both computer labs and collaborative spaces under daylight. For computer labs under daylight, an $E_{h}$ of 200 lx resulted in $69.2 \%$ of participants reporting imperceptible or noticeable glare and $30.8 \%$ of participants reporting disturbing or intolerable glare. Figure 4 displays the correlations between subjective glare assessments and $E_{h}$ for collaborative spaces under daylight. Similar as the correlations revealed in computer 
labs, an $E_{h}$ of 200 lx resulted in $21.6 \%$ of participants reporting disturbing or intolerable glare and the remaining reporting imperceptible or noticeable glare. Although UGR was revealed as the only glare index correlated with subjective evaluations, low percent of occupants reporting disturbing or intolerable glare led to flat slope of the correlation. When UGR varied between 4 and 26 , the range obtained from all the simulated and measured data, the percent of occupants reporting disturbing or intolerable glare differed from $12 \%$ to $19 \%$.

Table 8: Correlations between lighting predictors and the percent of participants reporting glare degrees.

\begin{tabular}{|c|c|c|c|}
\hline \multicolumn{4}{|c|}{ Computer Labs under Daylight } \\
\hline & Equation & p-value & $\mathrm{R}^{2}$ \\
\hline $\begin{array}{c}\text { Imperceptible } \\
\text { \& Noticeable }\end{array}$ & $\begin{array}{c}y=-18.059^{*} \\
\log _{10}\left(E_{h}\right)+110.8\end{array}$ & 0.0937 & 0.2007 \\
\hline $\begin{array}{c}\text { Disturbing } \\
\text { \& Intolerable }\end{array}$ & $\begin{array}{c}\mathrm{y}=18.059 * \log _{10}\left(\mathrm{E}_{\mathrm{h}}\right)- \\
10.8\end{array}$ & 0.0937 & 0.2007 \\
\hline \multicolumn{4}{|c|}{ Collaborative Spaces under Daylight } \\
\hline & Equation & p-value & $\mathrm{R}^{2}$ \\
\hline $\begin{array}{r}\text { Imperceptible } \\
\text { \& Noticeable }\end{array}$ & $\begin{array}{c}y=-16.591 * \log _{10} \\
\left(E_{h}\right)+116.607\end{array}$ & 0.0328 & 0.3484 \\
\hline $\begin{array}{c}\text { Imperceptible } \\
\text { \& Noticeable }\end{array}$ & $\begin{aligned} \mathrm{y}= & -0.3062 * \text { UGR } \\
& +89.0314\end{aligned}$ & 0.0902 & 0.2065 \\
\hline $\begin{array}{c}\text { Disturbing } \\
\text { \& Intolerable } \\
\end{array}$ & $\begin{array}{c}y=16.591 * \log _{10} \\
\left(E_{h}\right)-16.607 \\
\end{array}$ & 0.0328 & 0.3484 \\
\hline $\begin{array}{c}\text { Imperceptible } \\
\text { \& Noticeable }\end{array}$ & $\mathrm{y}=0.3062 *$ UGR-16.607 & 0.0902 & 0.2065 \\
\hline
\end{tabular}



Figure 4: Correlations between horizontal illuminance and the percent of participants reporting imperceptible or noticeable glare (red) and the percent of participants reporting disturbing or intolerable glare (blue) for collaborative spaces under daylight.

Table 9 shows the representative correlations between lighting predictors and glare sources - Question 3 in Table 1. For computer labs under daylight, reflections in monitors was the top glare source reported by 87 (71.3\%) participants. The percent of a screen with reflections over predetermined thresholds were tested against the percent of participants reporting reflections. The predetermined thresholds varied between 1 and $40 \mathrm{~cd} / \mathrm{m}^{2}$. The minimum luminance threshold correlated with subjective reported reflections was $16 \mathrm{~cd} / \mathrm{m}^{2}$ with a p-value of 0.03334 and $\mathrm{R}^{2}$ of 0.3463 (Figure 5). Luminance values between 16 and $40 \mathrm{~cd} / \mathrm{m}^{2}$ were also correlated with subjective reported reflections. As shown in Figure 5, even if all simulated reflections in monitors were lower than $16 \mathrm{~cd} / \mathrm{m}^{2}$, there were still $61.5 \%$ of participants reporting reflections. In other words, even minimal reflections caused by daylight led to a significant portion of participants to report reflections. According to the field measurements and calibration models, the monitors had low and high state luminance of 2 and $24 \mathrm{~cd} / \mathrm{m}^{2}$, respectively. $\mathrm{CR}_{\mathrm{V}}$ of 2.2 , lower than 4 recommended by ISO (9241-303, 2008), was obtained following Equation (1). Furthermore, the $\log _{10}$ of Band $\mathrm{Btd}_{\text {std }}$ was negatively correlated with the percent of participants reporting reflections. The Band $_{\text {std }}$ varied between 45 and $450 \mathrm{~cd} / \mathrm{m}^{2}$, and the maximum Band $_{\text {std }}$ of $450 \mathrm{~cd} / \mathrm{m}^{2}$ led to $50.1 \%$ of participants experiencing reflections in monitors.

Table 9: Correlations between lighting predictors and the percent of participants reporting glare sources.

\begin{tabular}{|c|c|c|c|}
\hline \multirow{8}{*}{$\begin{array}{c}\text { Computer } \\
\text { Labs } \\
\text { under } \\
\text { Daylight }\end{array}$} & \multicolumn{3}{|c|}{ Window as Glare Source } \\
\hline & Equation & p-value & $\mathrm{R}^{2}$ \\
\hline & $\mathrm{y}=8.245 * \mathrm{Band}_{\mathrm{COV}}+28.926$ & 0.0072 & 0.5228 \\
\hline & $\mathrm{y}=44.55 * \log _{10}\left(\mathrm{E}_{\mathrm{v}}\right)-38.33$ & 0.0755 & 0.2328 \\
\hline & \multicolumn{3}{|c|}{ Reflections in Monitors } \\
\hline & Equation & p-value & $\mathrm{R}^{2}$ \\
\hline & $\begin{array}{c}\mathrm{y}=-39.42 * \log _{10} \\
\left(\mathrm{Band}_{\text {std }}\right)+154.68\end{array}$ & 0.01 & 0.4884 \\
\hline & $\mathrm{y}=0.618 * \operatorname{Ref}_{16 \mathrm{per}}+61.5467$ & 0.0333 & 0.3463 \\
\hline \multirow{4}{*}{$\begin{array}{c}\text { Collaborat } \\
\text { ive Spaces } \\
\text { under } \\
\text { Daylight }\end{array}$} & \multicolumn{3}{|c|}{ Window as Glare Source } \\
\hline & Equation & p-value & $\mathrm{R}^{2}$ \\
\hline & $\mathrm{y}=33.415 * \log _{10}\left(\mathrm{E}_{\mathrm{v}}\right)-12.048$ & 0.0082 & 0.509 \\
\hline & $\mathrm{y}=\log _{10}\left(\mathrm{Band}_{\max }\right)-59.27$ & 0.009 & 0.5 \\
\hline \multirow{4}{*}{$\begin{array}{l}\text { Lecture } \\
\text { Halls } \\
\text { under } \\
\text { Electric } \\
\text { Lighting }\end{array}$} & \multicolumn{3}{|c|}{ Electric Lights } \\
\hline & Equation & $\mathrm{p}$-value & $\mathrm{R}^{2}$ \\
\hline & $\mathrm{y}=47.8 * \log _{10}\left(\mathrm{Band}_{\mathrm{std}}\right)-53.46$ & 0.0399 & 0.4006 \\
\hline & $\begin{array}{c}\mathrm{y}=-31.81 * \log _{10} \\
\left(\mathrm{Band}_{\mathrm{max}}\right)+173.98\end{array}$ & 0.0826 & 0.2792 \\
\hline
\end{tabular}

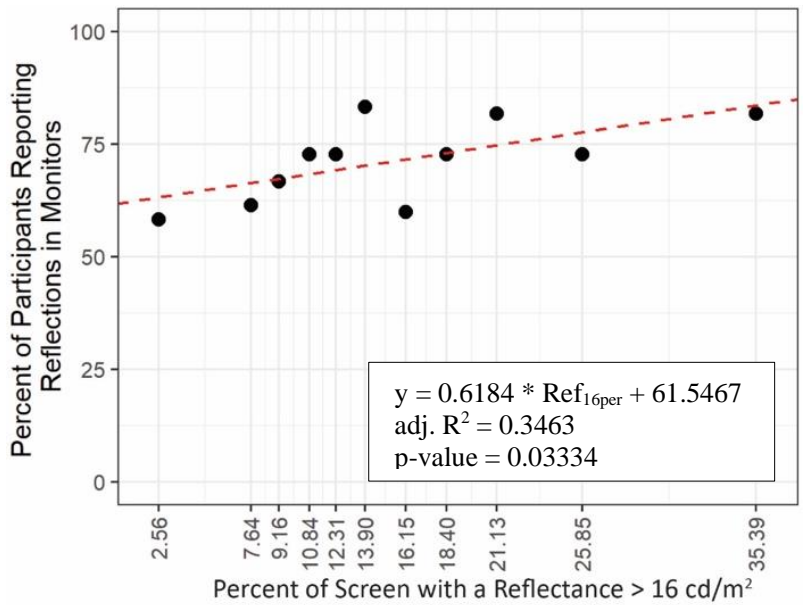

Figure 5: Correlation between the percent of reflections over $16 \mathrm{~cd} / \mathrm{m}^{2}$ and the percent of participants reporting reflections in monitors as glare source for computer labs under daylight.

Figure 6 shows the correlation between the $\log _{10}$ of $E_{v}$ and the percent of participants reporting windows as a glare source with a p-value of 0.0082 and $\mathrm{R}^{2}$ of 0.509 for collaborative spaces. An $\mathrm{E}_{\mathrm{v}}$ of $250 \mathrm{~lx}$ resulted in $68.1 \%$ of 
participants reporting windows as a glare source. $E_{\mathrm{v}}$ was also found as the predictor of glare caused by windows for computer labs under daylight with a p-value of 0.0755 and $\mathrm{R}^{2}$ of 0.2328 (Table 9 ). Other lighting predictors, like

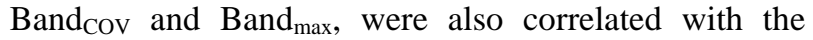
percent of participants reporting windows as a glare source for classrooms under daylight. In lecture halls under electric lighting, $B \operatorname{and}_{\max }\left(\mathrm{p}\right.$-value $=0.0399, \mathrm{R}^{2}=$ 0.4006) and $\mathrm{Band}_{\text {std }}\left(\mathrm{p}\right.$-value $\left.=0.0826, \mathrm{R}^{2}=0.2792\right)$ were correlated with the percent of participants reporting electric lights as a glare source.

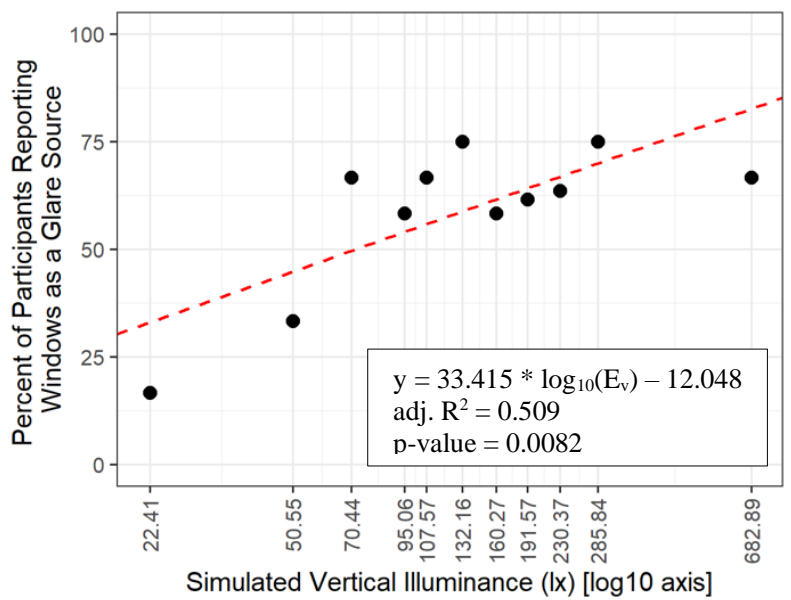

Figure 6: Correlation between vertical illuminance and the percent of participants reporting windows as a glare source for collaborative spaces under daylight.

\section{Inferential Statistics for Long-term Assessments}

This section presents representative correlations between annual lighting predictors and occupant subjective evaluations. Table 10 lists representative annual lighting predictors correlated with the percent of participants satisfied or dissatisfied with annual access to daylight at their regular seating positions for both computer labs and collaborative spaces under daylight. $\mathrm{E}_{\mathrm{h} \text {-mean }}$ and $\mathrm{E}_{\mathrm{v} \text {-mean }}$ averaged the annual mean horizontal and vertical illuminance under daylight of an individual's regular seating positions within one classroom. $\mathrm{E}_{\mathrm{m} \text {-mean }}$ averaged the annual mean daylight falling on monitors, and Mon $_{\text {DA500 }}$ averaged Daylight Autonomy at 500 1x (DA5001x) on monitors of a participant's regular seating positions. Figure 7 shows the positive correlation between the $\log _{10}$ of $E_{v \text {-mean }}$ and the percent of participants satisfied with annual access to daylight in red with a p-value of 0.0055 and $\mathrm{R}^{2}$ of 0.5484 , as well as the correlation between the $\log _{10}$ of $\mathrm{E}_{\mathrm{v} \text {-mean }}$ and the percent of participants dissatisfied with annual access to daylight in blue with a p-value of 0.0176 and $\mathrm{R}^{2}$ of $0.4256 . \mathrm{E}_{\mathrm{v} \text {-mean }}$ wherein 202 lx predicted that no occupant dissatisfied with annual access to daylight. And $\mathrm{E}_{\mathrm{v} \text {-mean }}$ of $200 \mathrm{~lx}$ predicted $85 \%$ occupants' satisfaction with daylight in computer labs. For collaborative spaces, however, the $\log _{10}$ of $\mathrm{E}_{\mathrm{m} \text {-mean }}$ was negatively correlated with the percent of participants satisfied with annual access to daylight ( $\mathrm{p}$-value =

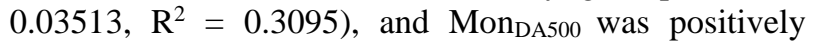
correlated with the percent of participants dissatisfied with annual access to daylight ( $\mathrm{p}$-value $=0.05406, \mathrm{R}^{2}=$
0.3124) (Table 10). According to the extracted correlation $\mathrm{E}_{\mathrm{m}-\mathrm{mean}}$ of $100 \mathrm{~lx}$ resulted in $70.7 \%$ of occupants satisfied with annual mean daylight falling on their monitors, while Mon $_{\text {mean }}$ of $300 \mathrm{~lx}$ lowered the satisfaction percent to $60.3 \%$. Given that the monitor pixel brightness was low, the required $\mathrm{Mon}_{\text {mean }}$ was also low. Nonetheless, these correlations reveal the necessity of controlling the amount of light falling on monitors.

Table 10: Correlations between annual mean lighting predictors and the percent of participants satisfied or dissatisfied with annual accessible daylight.

\begin{tabular}{|c|c|c|c|}
\hline \multicolumn{4}{|c|}{ Computer Labs under Daylight } \\
\hline & Equation & p-value & $\mathrm{R}^{2}$ \\
\hline Satisfied & $\mathrm{y}=48.3 * \log _{10}\left(\mathrm{E}_{\mathrm{v} \text {-mean }}\right)-26.17$ & 0.0055 & 0.5484 \\
\hline Dissatisfied & $\begin{array}{c}\mathrm{y}=-54.46 * \log _{10}\left(\mathrm{E}_{\mathrm{v}-}\right. \\
\text { mean })+125.53\end{array}$ & 0.0176 & 0.4256 \\
\hline \multicolumn{4}{|c|}{ Collaborative Spaces under Daylight } \\
\hline & Equation & p-value & $\mathrm{R}^{2}$ \\
\hline Satisfied & 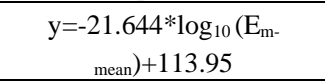 & 0.0351 & 0.3095 \\
\hline Dissatisfied & $\mathrm{y}=31.802 * \mathrm{Mon}_{\mathrm{DA} 500}+13.022$ & 0.0541 & 0.3124 \\
\hline
\end{tabular}

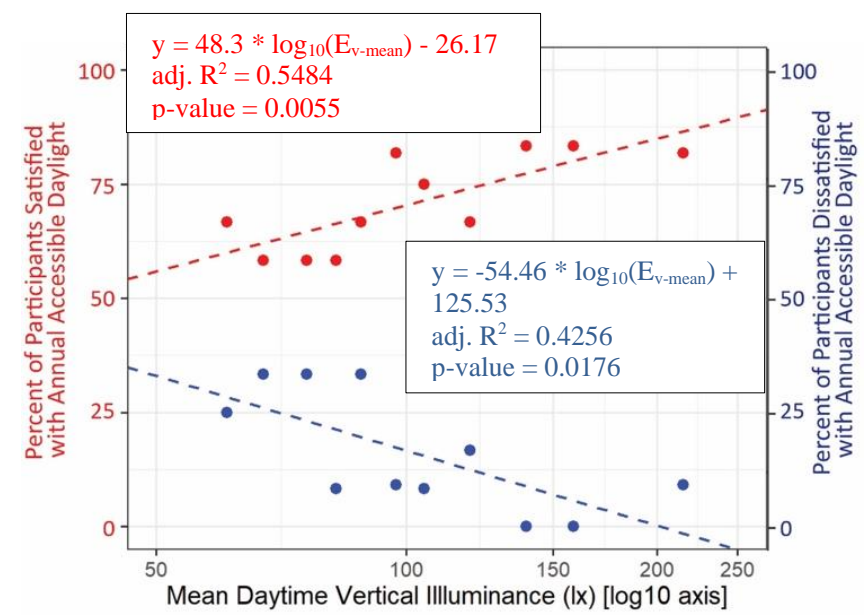

Figure 7: Correlations between simulated annual mean daytime vertical illuminance and the percent of participants satisfied with (red) or dissatisfied with (blue) annual access to daylight for computer labs under daylight.

Finally, Table 11 shows correlations between annual mean lighting predictors and the percent of participants agreeing or disagreeing with lighting aids on productivity. For computer labs under primary electric lighting, $\mathrm{E}_{\mathrm{h} \text {-mean }}$ was positively correlated with the percent of participants agreeing with lighting aids on productivity with a $\mathrm{p}$-value of 0.0241 and $\mathrm{R}^{2}$ of 0.6058 , as shown in Figure 8. For lecture halls under electric lighting, $\mathrm{E}_{\mathrm{v} \text {-mean }}$ was negatively correlated with the percent of participants disagreeing that lighting aids on productivity with a p-value of 0.0425 and $\mathrm{R}^{2}$ of 0.3908 . Participants preferred consistent electric lighting conditions to varying daylighting conditions while working.

Table 11: Correlations between annual mean lighting predictors and the percent of participants agreeing or disagreeing with lighting aids on productivity. 


\begin{tabular}{|c|c|c|c|}
\hline \multicolumn{4}{|c|}{ Computer Labs under Electric Lighting } \\
\hline \multirow{2}{*}{ Agree } & Equation & $\mathrm{p}$-value & $\mathrm{R}^{2}$ \\
\cline { 2 - 4 } & $\mathrm{y}=148.5 * \log _{10}\left(\mathrm{E}_{\mathrm{h} \text {-mean }}\right)-331.14$ & 0.0241 & 0.6058 \\
\hline \multicolumn{4}{|c|}{ Lecture Halls under Electric Lighting } \\
\hline \multirow{2}{*}{ Disagree } & Equation & $\mathrm{p}$-value & $\mathrm{R}^{2}$ \\
\cline { 2 - 4 } & $\begin{array}{c}\mathrm{y}=-48.14 * \log _{10}\left(\mathrm{E}_{\mathrm{v}-}\right. \\
\text { mean })+127.35\end{array}$ & 0.0425 & 0.3908 \\
\hline
\end{tabular}



Figure 8: Correlations between annual mean horizontal illuminance and the percent of participants agreeing with lighting aids on productivity for computer labs under electric lights.

\section{Conclusion}

As the study included six classrooms under primary diffuse daylight without direct sunlight penetration, participants experienced contrast-based glare most often. DGP does not detect glare according to subjective perception, which confirms the conclusion drawn from office buildings under tropical climates (Hirning et al., 2017; Jakubiec et al., 2018). By proposing $E_{\mathrm{v}}$ and $E_{h}$, this study shows the possibility of employing simple and direct lighting predictors for creating comfortable lighting environments in the tropics. The coefficient of determination $\left(\mathrm{R}^{2}\right)$ in this study varied between 0.2007 and 0.6058 , most of which were moderate effect $\left(R^{2}>\right.$ $0.25)$ and strong effect $\left(R^{2}>0.64\right)$. However, these values outperform previous studies with the maximum $\mathrm{R}^{2}$ varying between 0.212 and 0.35 (K. G. Van Den Wymelenberg, 2012; Jakubiec, Reinhart, \& Wymelenberg, 2015; Mahić et al., 2017).

Second, reflections in monitors, one type of glare that is normally difficult to quantify (Jakubiec, Reinhart, \& Wymelenberg, 2015), is significantly correlated with subjective responses in our study. However, as mentioned in the result section, there were high percent of participants reporting reflections in monitors even without reflections over $16 \mathrm{~cd} / \mathrm{m}^{2}$. One explanation is due to the glossy monitors in the computer labs. The monitors within computer labs under daylight were glossy screens with a smooth outer polarising layer, more specularly reflective than matte screens. Another explanation is due to the monitor arrangement. All monitors faced towards one side of the double-loaded windows, which can easily lead window reflections to appear in the monitors. The relative orientation between monitors and windows play an important role in subjective visual comfort (Kong, Utzinger, Freihoefer, \& Steege, 2018).

For classrooms access to daylight, the authors recommend horizontal illuminance of $150 \mathrm{~lx}$ and vertical illuminances of $200 \mathrm{~lx}$ as design thresholds to strike a balance between lighting comfort and daylight glare. Annual mean vertical illuminance of $200 \mathrm{~lx}$ during the daytime leads to $85 \%$ of occupants satisfied with annual access to daylight. For classrooms where screen-based tasks predominate, daylight falling on monitors should be limited to $100 \mathrm{~lx}$ to satisfy $70 \%$ of occupants and reduce reflections in monitors. For classrooms under only or primary electric lighting, horizontal illuminance of $200 \mathrm{~lx}$ and vertical illuminance of $250 \mathrm{~lx}$ are recommended to achieve visual comfort for $60 \%$ of occupants and visual discomfort for $7 \%$ of occupants. More importantly, designers can utilize the correlation equations - listed in Tables 7 to 11 - from our study to create comfortable and satisfying lighting environments for the predetermined percent of occupants by controlling these simple, direct lighting predictors.

\section{Limitations and Future Work}

One limitation of this work is the exclusion of occupants while simulating instantaneous luminance distributions. For computer labs, the exclusion of occupants potentially increases reflection areas in monitors, given that occupants normally block a person-shape reflection of windows behind. Another limitation is the number of campuses where data collection was conducted. Future studies should be conducted at other universities to either confirm the narrow range of interior lighting distributions and low monitor brightness or enrich and enlarge both interior and monitor lighting ranges.

\section{Acknowledgement}

This work was supported by the Singapore Building Construction Authority (BCA), Green Building Innovation Cluster (GBIC) Research and Development Grant under grand number GBIC-R\&D / DCP 05. Any optinons expressed herein are those of the authors and do not reflect the views of the IDC. The authors are extremely grateful to Denise Kwok and Harry Wong from the BCA for facilitating access to three of the classrooms studied herein. The authors additionally thank all 439 students and instructors for their participation.

\section{References}

Kong, Z., Utzinger, D. M., Freihoefer, K., \& Steege, T. (2018). The impact of interior design on visual discomfort reduction: A field study integrating lighting environments with POE survey. Building and Environment, 138(April), 135-148.

Kong, Z., Utzinger, D. M., \& Humann, C. (2018). Evaluation of a hybrid photo-radiometer sky model compared with the Perez sky model. Energy and Buildings, 178, 318-330.

Jakubiec, J. A., Quek, G., \& Srisamranrungruang, T. (2018). Towards Subjectivity in Annual ClimateBased Daylight Metrics Towards Subjectivity in Annual Climate-Based Daylight Metric 